\title{
Automated Corridor Lighting Control System
}

\author{
Mohammed Ahmed ${ }^{1}$ and Jemal Worku ${ }^{2}$ \\ Jimma Institute of Technology, Jimma, Ethiopia
}

\begin{abstract}
The Paper is aims to design a corridor lighting control system to make the system autonomous and energy saving. Automatic switching on/off of lights is working as per the presence of people in the building corridors.Push buttons are strategically placed to the entry and exit of the people. Depending on the number of people passing through the counter goes up/down and stores the corresponding value in the register which is referred to by the comparator which controls the tripping of the lighting circuit accordingly. The light will come on when the first person enters the corridor and does not switch off until the counter value drops to 0.
\end{abstract}

\section{Introduction}

The need of electricity is increasing as the population and industrialization growing. The design of private buildings, street lines, factories and commercial buildings lighting system are doing as per the national and international standard codes. In some cases, the design of building lighting system is not considered the specific application of a building. This will leads the customer for over power consumption and power loss.

In Ethiopia, inappropriate consumption of power is common in the commercial institutions such as universities, collages, health centers, factories and others. They are powering ON street lights, corridor lights, and office and class room lights for a long time when a human is not available. It results not only the institution to pay money for misused powers but also it limits power suppliers to satisfy and reach more customers.

Recently, Green issue has been raised as a hot topic where most of the researchers and engineers are involving themselves in finding a solution to reduce the energy usage at the same time increasing their product efficiency. Smart control systems have being assisting and implemented in different sector of developed world.

People are told to turn OFF the lights when are not in use - one of the best way to save energy. These days, many buildings of developed countries are integrated with automated lighting where people do not even have to toggle the switch to save energy. With the aid of automated lighting, the lights are turn ON if there is person in the room and turn OFF when there is none - close loop control system. Some of the smart lighting systems are add-on with the extra feature where it will control the lights luminance correspond to the ambient lights. This method is uncommon in most of the buildings today and thus there is a big opportunity to save more energy with the smart lighting system.

The most common form of electric lighting control is the on/off "toggle" switch. Other forms of lighting control include occupancy sensors, daylight sensors, clock switches, a variety of manual and automatic dimming devices, and centralized controls. The selection of sensor and type of lighting control depends on the application and the area where it is used [1].

This system can effectively work in areas where electricity is excessively used especially, during night time in corridors of hostels, hospitals etc. The proposed PLC based system will remain OFF when there is no presence of human being and will activate [2, 4] upon the arrival of human being in specified area. This presence will be detected by push button at input side. One of the biggest utility concerns is the fact that by detecting the presence of person whenever enters in the area of corridor of premises, the tube light will remain in ON state, otherwise it will remain OFF. The switching action of tube light will take place by using relay. The staircase timer allows reduction of energy spent for lighting [6]. Instead of having the staircase and corridors permanently light, the lighting is reduced to a pre-defined amount of time after one of the push-buttons connected to the timer is pressed. Energy efficient corridor illumination in commercial and residential buildings is becoming increasingly important in the energy conservation era.

Now a day, Jimma Institute of Technology building lighting control system is manually switching ON and OFFthe switches that are belonged at the wall of the buildings by the users. Most of the time, corridor light and class room light fittings are operating without the human is not available [3]. Many corridors light operate 24 hours a day, 365 days a year and typically have very low occupancy rates. This problem will reduce the life of light fittings, power loss, over power consumption and more meter reading $[15,16]$.

\section{Methodology}

Ladder logic programming looks similar to the wiring diagram of the electromechanical relay-based control circuits that PLCs replace. 


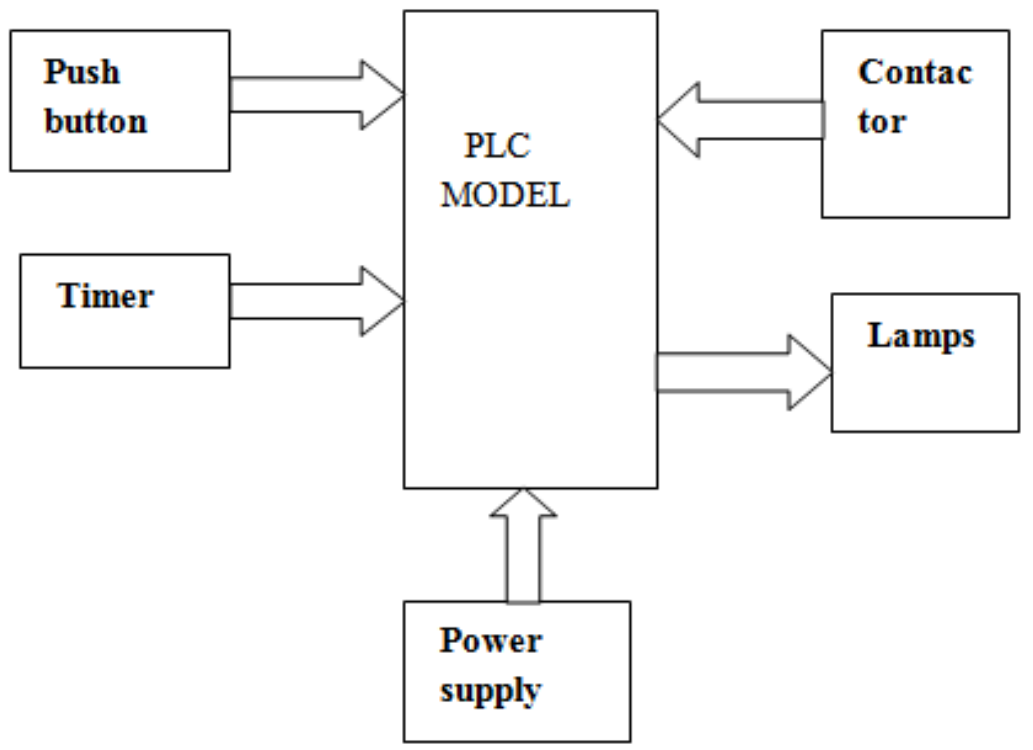

Fig. 1. Block Diagram of Power Management Using PLCs

A PLC is a digital operating electronic apparatus which uses a programmable memory for internal storage of instruction for implementing specific function such as logic, sequencing, timing, counting and arithmetic to control through analog or digital input/output modules various types of machines or process. There are different types of PLC'S used for various applications. In the present work, an XD 26 PLC [5, 15] is used to control the Smart corridor Lighting System because of its user friend and expandable features.

\section{PLC Principle of Operation}

Most PLCs on the market are microprocessor-based circuits. These PLCs read the status of all the inputs (i.e., switches) and then execute the user-written ladder logic program to determine the final update for the outputs (i.e., bulb).

The PLC inputs are isolated and level translated using opto-isolators and connected to the ports of the microcontroller. The PLC outputs are connected to buffers and relays to enable connecting the same to output elements as shown in the picture below. Different control techniques have been proposed for street lighting controller during seasonal variation. It is common to use relays to make simple logical control decisions. The relays allow power to be switched on and off without a mechanical switch. The development of low cost computer has brought the most recent revolution, the Programmable Logic Controller (PLC). With the advent of the PLC; it has become the most common choice for manufacturing controls. A PLC is a digital operating electronic apparatus which uses a programmable memory for internal storage of instruction for implementing specific function such as logic, sequencing, timing, counting and arithmetic to control through analog or digital input/output modules various types of machines or process. There are different types of PLC'S used for various applications. In the present work, an XD 26 PLC is used to control the Smart corridor Lighting System [8 - 11].

PLCs are typically chosen for small discrete applications where high level ruggedness and reliability is required. They offer high speed sequential and logical control capabilities and are very good control solutions for real time applications. A PLC retains its operating system, user programs, and some data in retentive (nonvolatile) memory. PLC has not only replaces the relay but ha Nowadays computer control and information system technology is applied widely in most of the process industry, because it may produce significant technical and economic benefits. Process control information systems assist operating personnel in producing the required output of products with minimum quality variations, least consumption of the raw material and energy, and maximum efficiency. Centralization process control combined with increased mechanization has resulted in improved productivity [1]. Now a day's advanced control systems like PLCs are extensively used in the industries.

In the present work, an XD 26 PLC $[5,15]$ is used to control the Smart corridor Lighting System. The numbering for the XD 26 PLC is given in such a way that as it is having sixteen Digital of which six are analog inputs and ten discrete static relay outputs. Every PLC has associated programming software that allows the user to enter a program into the PLC. Before a PLC can perform any control task, it must be programmed to do so. 


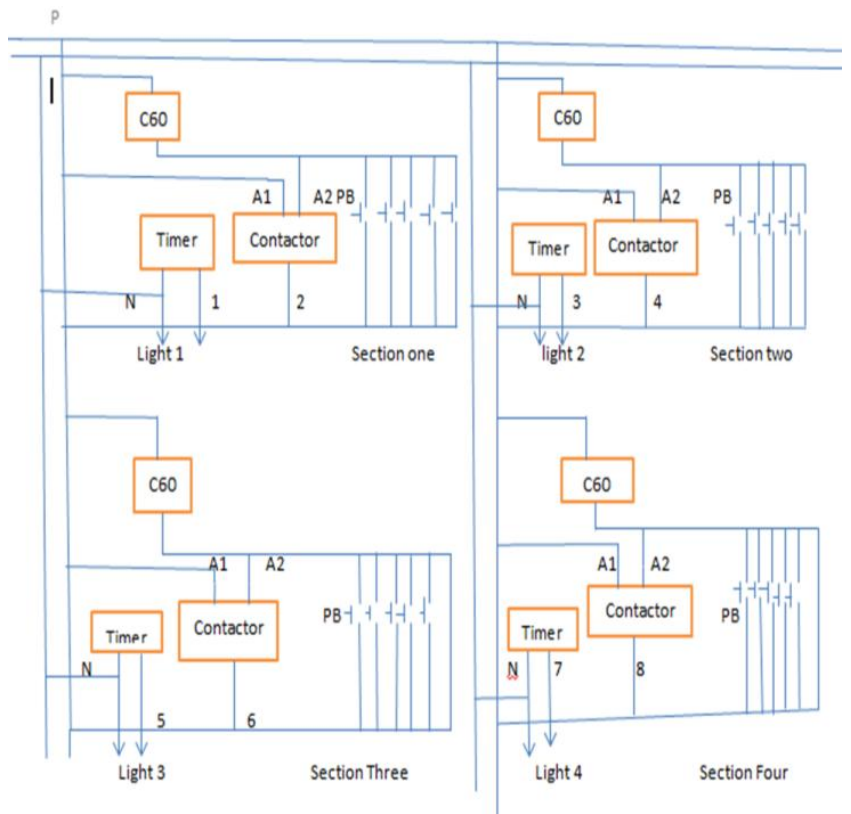

Fig. 2.Electrical Circuit Wiring Diagram

Fig. 2 shows the control implemented as a wiring diagram using two switches (switch 1 is in parallel with switch 2 is installed staircase) and a light bulb.

Switch 1 and Switch 2 are in the OFF position in Fig. 3. The Timer T009 should be adjusted first by the persons. If the Switch 1 is actuated, then the upper circuit will switch ON the bulb, then timer has to be count until it stops its adjusted value and makes the Light to be OFF. Here the two push buttons are connected in parallel to operate in OR gates. This is used to give different service for more than one person. When another person is come in the same direction before the first light is OFF, the person should press the next push button to get light or switched Off the light, the timer makes the light switched OFF until it reaches its adjusted value Switch 2 is actuated it will open the upper circuit and close the bottom circuit. However, switch 1 is already open at the bottom circuit, so the bulb will not glow. Actuating switch 1 again will close the bottom circuit and the bulb will glow.

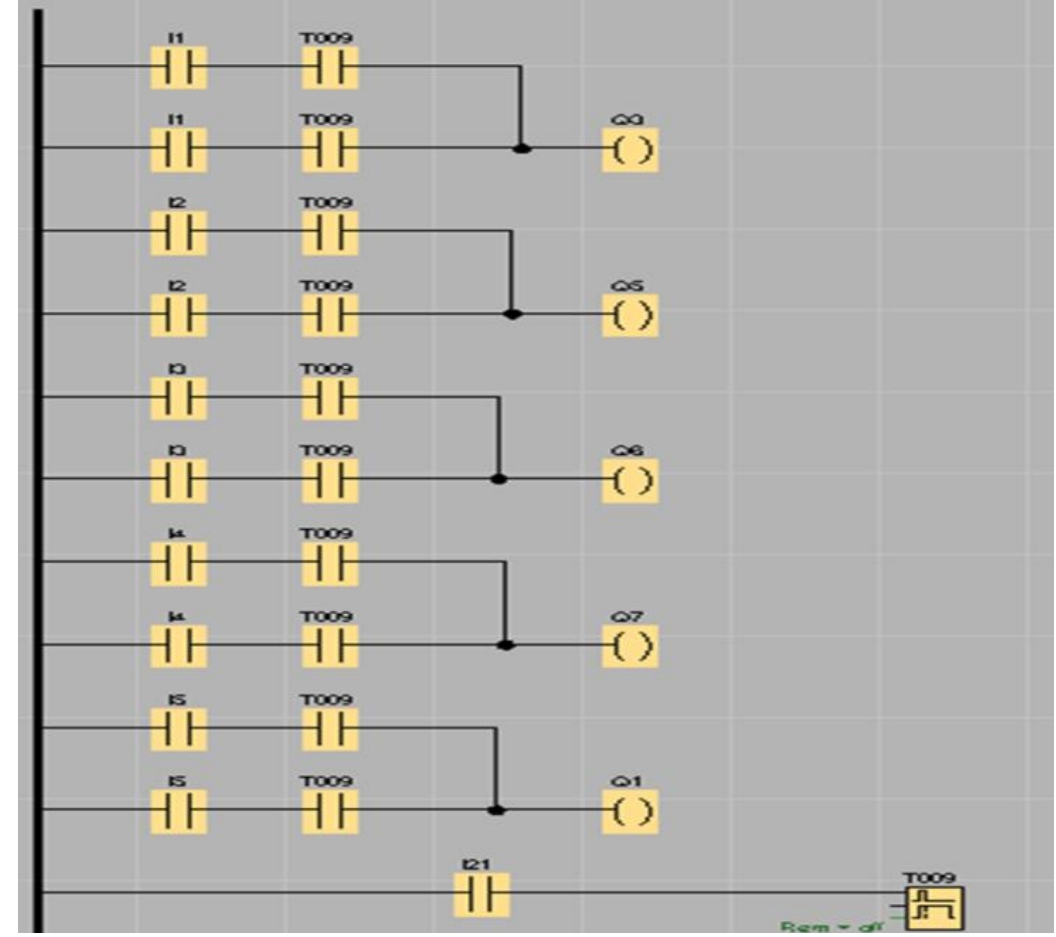

Fig. 3. Simulation Result for One Section 


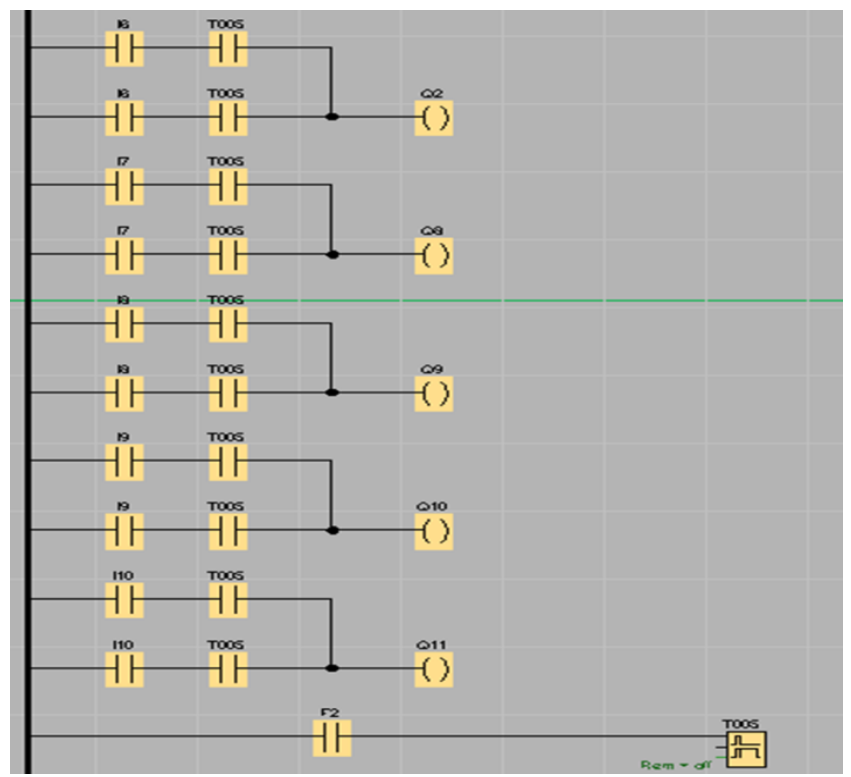

Fig. 4.Simulation Result for Second Section

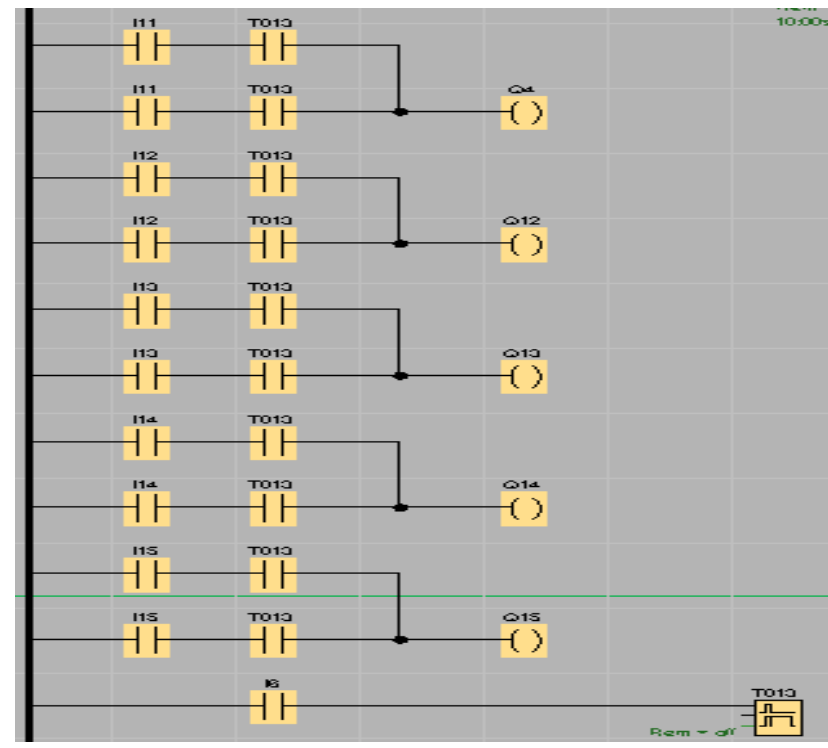

Fig. 5. Simulation Result for Third Section

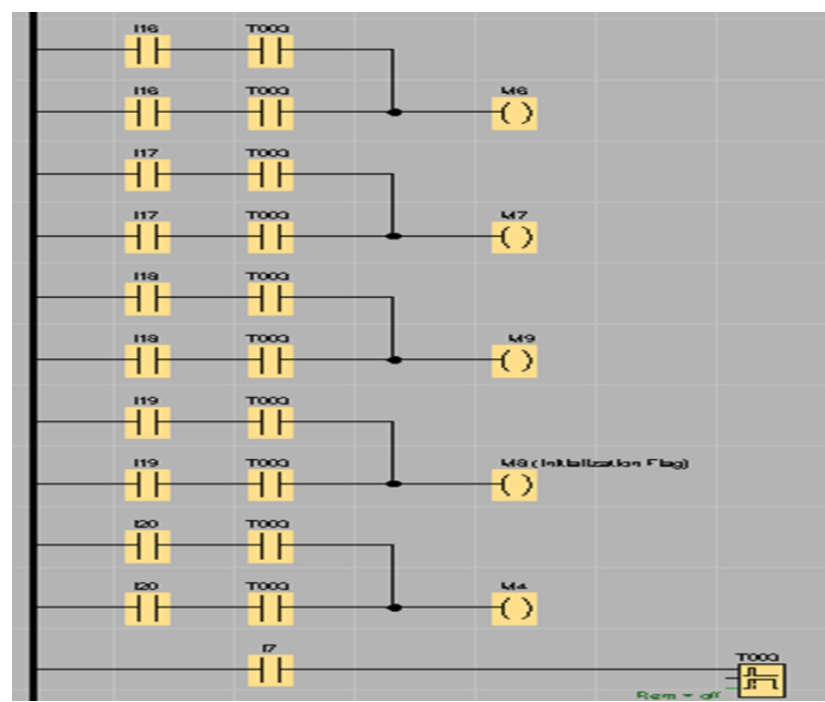

Fig. 6.Simulation Result for Section Four 
Fig. 4.the Timer T005 and push button I6 to I10 designed for the second section of the building. When the person wants to enter the corridor, the same principle can be applied to switch ON the light to section one. To switch ON or OFF the light, the Timer should be adjusted at once. Then, the person can use either of push button to switch ON or OFF the light, If one push button is closed or pressed the light will be glow and the timer switched of the light when it reaches its final adjusted value.

Timer $\mathrm{T}_{013}$ and push button $\mathrm{I}_{11}$ to $\mathrm{I}_{15}$ designed for the third section of the building, the principle is the same with section one and two as shown Fig. 5. The Timer $T_{003}$ and push button $I_{16}$ to $I_{20}$ are designed for the fourth section of the building and principles works the same with above, But different person come at different direction in these case the designed circuit holds good in Fig. 6.

Generally, the electric power is saved by using timer and push button which is integrated with programmable logic controller.

\section{Energy saving Using PLC}

The four existing corridor light sources (T16 tube light of $40 \mathrm{~W}$ ) have working for $12 \mathrm{hrs}$ per day. In one corridor there are 4 fixtures each has 4 fluorescent, the power wattage for one fluorescent is $40 \mathrm{~W}$. Therefore, the total power wattage for one corridor is $640 \mathrm{~W}$ and $2803.2 \mathrm{KWH}$ per year.

The light in the corridor are kept $\mathrm{ON}$ for 12 hours in a day and 365 days in a year with the unit energy cost of electricity, 0.25 cents per kwh. The annual energy cost of lighting for a single corridor of a wing is 480 Birr/year.In Varnerobuilding of ground floor wing 1, there are 5 corridors and floors. Therefore, the total cost of corridor light of the whole building having four wings is 48000 Birr/year.

\section{Conclusion}

The proposed controller gives fast, reliable, and power efficient smart lamp switching based on the need of the person. The simulated results are also verified experimentally by using push button, timer which controls the light. It turns out most reliable and time efficient way to switch ON/OFF corridor lights. It provides an effective measure to save energy by preventing unnecessary wastage of electricity, caused due to manual switching or lighting of corridor lights when it is not required. The system is versatile, extendable and totally adjustable to user needs. The developed lighting control system is needs a simple modification to fit in existing wiring setup.

\section{References}

[1]. E. El-Shirbeeny,"Proposal for Automating Street Lighting System of Abu Dhabi/AI Ah highway", EPRL01-1, ADWEA, Abu Dhabi, UAE, 2001.

[2]. Pantoni R.P.,Brandao, D., "A geocast routing algorithm intended for street lighting system based on wireless sensor networks", 9th IEEE/IAS International Conference on Industry Applications (INDUSCON), 2010, pp. 1 - 6

[3]. Reluz Program, "National Program of Efficient Public Lighting and Traffic Lights".Available:http://www.eletrobras.gov.br/EMProgramas-Reluz,Jan. 2010.

[4]. Ei-Shirbeeny, E.H.T.; Bakka, M.E. "Experimental Pilot Project for Automating Street Lighting System in Abu Dhabi Using Power Line Communication". Proceedings of the 10th IEEE International Conference on Electronics, Circuits and Systems, Vol. 2, p.743 746, Dec. 2003.

[5]. Sungkwan C.,Dhingra, V. "Street lighting Control Based on Lon Works Power Line Communication Power Line Communications and Its Applications", IEEE Symposium, 2008.

[6]. JayashriA.Bangali, ArvindD.Shaligram,"Energy Efficient Lighting Control System Design For Corridor Illumination”, International Journal of Scientific \&Engineering Research, Vol. 3, Issue 4, April-2012, and ISSN 2229-5518.

[7]. G.W. Barriquello, C.H. Campos, A. Do Prado, "An Intelligent System for Street Lighting Monitoring and Control",CongressoBrasileiro de Eletronica de Potenci, Brazil, Bonito, 2009.

[8]. Caponetto R., DongolaG., Fortuna L., Riscica N. and ZufacchiD., "Power Consumption Reduction in A Remote Controlled Street Lighting System", International Symposium on Power Electronics, Electrical Drives, Automation and Motion (SPEEDAM 2008), Ischia, June 2008, pp. 428-33.

[9]. Chen, P.-Y., Liu, Y.-H., Yau, Y.-T. and Lee, H.-C., "Development of Energy Efficient Street Light Driving System", IEEE International Conference on sustainable Energy Technologies (ICSET 2008), Singapore, Nov. 2008, pp. 761

[10]. Chung, H.S.H., Ho, N.M., Hui, S.Y.R. and Mai, W.Z., "Case Study of a Highly-Reliable Dimmable Road Lighting System with Intelligent Remote Control", European Conference on Power Electronics and Applications, Dresden, 2005.

[11]. E. El-Shirbeeny, "Pilot Project Far Using Power Line Communications in Controlling Street Lighting Report", EPRL01-21, ADWEA, Abu Dhabi, UAE, 2001.

[12]. PantoniR.P.,Brandao D., "A Confirmation-Based Geocast Routing Algorithm for Street Lighting System”, Industrial Electronics (ISIE), 2011 IEEE International Symposium on, On page(s): 841 - 846

[13]. Reinhard M. and Andreas R.,"An Energy Efficient Pedestrian Aware Smart Street Lighting System”, International Journal of Pervasive Computing and Communications, Vol. 7, No. 2, 2011, pp. 147-161

[14]. Wang C., Zhang D.L., Qin H.L. et al., "HPS Street Lighting Lamp Networking over Power-lines", PowerCon 2006, International Conference on Power System Technology, Oct. 22-2, Page(s): 1 - 5.

[15]. Li-Ling Wang, Hong-Ying Wei, "Development of a distributed control system for PLC-based Applications", International Conference on Machine, 2010, Vol. 2, Page(s): 906 - 909.

[16]. Mohammed Ahmed, GezahegnShituneh, et al., "Contingency Analysis of Ethiopia's 230 kV Transmission Network”, International Journal of Engineering Technologies, Vol. 1, No. 4, 2015. 